\title{
CONSTITUCIONALIZAÇÃO SIMBÓLICA OU CONSTITUCIONALIDADE-SIMULACRO? EXCLUSÃO, PERIFERIZAÇÃO E SOBERANIA POPULAR NO DIREITO CONSTITUCIONAL BRASILEIRO
}

\author{
FERNANDO A. GOMES*
}

\begin{abstract}
RESUMO: O artigo explica o significado da constitucionalização simbólica situado no intenso debate entre direito e política na formação da Constituição. Ressalta, também, a natureza semelhante do caráter simbólico reproduzido na Constituição e na política, onde uma agenda ideológica é estruturada para manutenção do poder instituído. Além disso, evidencia os efeitos ilusórios do tratamento "sagrado" do poder constituinte. Reconhece, contudo, que a complexidade da discussão provoca uma abertura cognitiva a qual a positivação do direito tenta resolver.

PALAVRAS-CHAVE: Constituição; Direito; Política; Soberania.
\end{abstract}

ABSTRACT: The article explains the symbolic constitution meaning which is present in the intense debate between law and politics in the formation of the Constitution. Points out, too, the symbolic similar character that is reproduced by the Constitution and in politics, where an ideological agenda is structured to maintain the authorities. Moreover, shows the effects of illusory "sacred" treatment of the constituent power. It recognizes, however, that the complexity of the discussion leads to a concrete normative opening that ruled and regulated rights try to solve.

KEYWORDS: Constitution; Law; Politics; Sovereignty.

Seguindo as pistas semânticas deixadas pela evolução do significado de constituição no pensamento político-jurídico, deparamo-nos com evidências de que sua moderna acepção no âmbito do direito público tem origem no encontro de duas tradições ligadas a diferentes significados do termo constitutio, que se desenvolveram paralelamente até o início das grandes revoluções do século 18. De acordo com esta compreensão, a idéia organicista de constituição como conformação saudável ou doentia do corpo - inclusive e sobremaneira no sentido hipostasiado de "corpo social" - se combinou à conotação propriamente jurídica da expressão, designativa de todos os atos a que se atribuísse força legal. ${ }^{1}$ O resultado desta fusão, em última instância, nada mais é que o próprio

${ }^{*}$ Mestre em Direito Constitucional e Doutorando em Direito pela UFMG. Assessor jurídico da Procuradoria
Geral do Município de Belo Horizonte. Advogado.
${ }^{1}$ Um dos mais importantes trabalhos sobre esta evolução é de STOURZH, Gerald. Constitution: Changing 
conceito moderno de constituição: “uma lei positiva que serve de fundamento para o direito positivo mesmo, e que determina, por causa disto, como pode ser organizado o poder político, e como ele pode ser exercido de forma jurídica e com restrições desta mesma natureza". ${ }^{2}$

Em uma leitura guiada pela concepção teórico-sistêmica do direito e da sociedade, os indícios fornecidos por esta evolução semântica corroboram, no geral, a tese segundo a qual as constituições atuais realizam uma atrelagem entre as estruturas (contingentes) do direito positivo e da política institucionalizada num contexto social de crescente autonomização dos respectivos sistemas. ${ }^{3}$ Por um lado, é bem certo que tal concepção pode ainda enfrentar resistências várias e permanecer mais ou menos controversa. Seja como for, está fora de questão o entendimento segundo o qual as limitações recíprocas entre direito e política constituem o cerne operativo dos textos constitucionais, ${ }^{4}$ e de que, através dessas limitações, asseguram-se, simultaneamente, a vigência de princípios jurídicos insuscetíveis de negociação política e o respeito às decisões políticas conformadas aos procedimentos instituídos juridicamente. Além disso, e ainda segundo a tese do "acoplamento estrutural”, as constituições "resolvem" o problema da fundação da ordem jurídico-política, invisibilizando-o: em outras palavras, as constituições fornecem uma solução política para a auto-referencialidade do sistema jurídico (que já não pode invocar o fundamento de uma “ordem superior”, divina, natural-racional ou autoritária) e uma solução jurídica para a auto-referencialidade do sistema político (que não pode mais recorrer diretamente à ficção da volónté générale), estabelecendo entre eles uma relação de co-implicação que se manifesta sob a forma de Estado constitucional. ${ }^{5}$

Também não se discute o fato de a constituição assumir significados diferentes segundo a perspectiva do sistema desde o qual se a enfoca: ${ }^{6}$ para o direito, ela é a norma fundamental suprema; para a política, meio de transformação da realidade e de fixação de ideais políticos. Sua própria condição de instrumento de acoplagem entre âmbitos sociais funcionalmente especificados e diversos entre si evidencia essa dualidade fundamental. Contudo, ainda que essa representação bífida das constituições aparentemente indique uma propensão a confundirem-se os mecanismos operacionais da política e do direito, num tipo de regulamento unitário de ambos, ${ }^{7}$ é precisamente a separação e

Meanings of the Term from the Early Seventeenth to the Late Eighteenth Century, in BALL, Terence e POCOCK, John G.A., Conceptual Change and the Constitution. Lawrence: University Press of Kansas, 1988. ${ }^{2}$ LUHMANN, Niklas. Das Recht der Gesellschaft. Frankfurt am Main: Suhrkamp, 1993, p. 472.

${ }^{3}$ Cf. LUHMANN, Niklas. La costituzione come acquisizione evolutiva, in Zagrebelsky, Gustavo et alii (eds.), Il Futuro della Costituzione. Torino: Einaudi, 1996.

${ }^{4}$ As vantagens desse arranjo se devem a que acoplamentos estruturais permitem um sistema dar por supostas determinadas características de seu entorno, confiando nelas como em parte de sua própria estrutura e, dessa forma, operando redução de complexidade.

${ }^{5}$ Cf. LUHMANN, Niklas. Das Recht der Gesellschaft, op. cit., p. 478 (sobre a verdadeira função de acoplamento ser do Estado fundado no/pelo direito: „Nicht der Text allein, sodern nur der Verfassugsstaat erfüllt die Kopplungsfunktion.”).

${ }^{6}$ Observar = distinguir e indicar. Nessa operação, o observador sempre estará de um lado...

${ }^{7}$ Como pode nos fazer crer uma longa tradição consolidada a partir do início da idade Moderna, segundo a qual podem considerar-se o político e o jurídico como um sistema unitário, em grande parte devido à correspondente natureza jurídico-política do Estado. Sobre este ponto, vide LUHMANN, Niklas. La costituzione 
impermeabilidade entre os sistemas político e jurídico que, garantindo um maior potencial de mútua reatividade entre estes, ${ }^{8}$ determina o sentido moderno das constituições. Em todo caso, a política deve seguir sendo o modo de mobilização do poder para a obtenção de decisões coletivamente vinculantes, e o direito, a forma de estabilização das expectativas de expectativas normativas congruentemente generalizadas, cada qual operando na recursividade dos respectivos códigos e segundo seus programas típicos. O decisivo para que uma constituição cumpra integralmente sua função evolutiva é, acima de tudo, aquilo que tem lugar sob a máscara da legitimidade jurídica da ordem política (ou vice-versa): a diferenciação funcional e o fechamento operacional dos sistemas político e jurídico.

Dito de forma tautológica - e portanto mais direta e proporcionalmente menos informativa: direito é direito, política é política, e uma constituição só pode ser constituição moderna se se apóia ao menos em parte nesta realidade. É esta a razão pela qual há sempre um comprometimento da "força normativa" da constituição toda vez que ingerências políticas ou econômicas logram determinar, em situações de aplicação ou no curso do processo legiferante, mediante manobras não autorizadas juridicamente ou que contrariem princípios jurídico-normativos fundantes, o que é e o que não é o direito - interferindo na (= corrompendo a) particular esfera de resolução de problemas deste. Sob este aspecto, o verdadeiro - e mais grave - problema da redução dos conflitos de poder político à dimensão puramente econômica das negociatas envolvendo a utilização de cargos, orçamentos, votos e outros meios institucionais para a aquisição de vantagens indevidas não é o desgaste ético, o esfacelamento moral ou a descrença maciça que se abatem sobre os atores que protagonizam tais episódios, nem sequer uma correlata "crise de legitimidade" mais ampla, que inclua o direito, mas sim a crescente incapacidade de se manterem os limites reciprocamente condicionados da política e do direito, sobretudo em virtude da tendência predominante de se tratarem as modificações jurídicas como forma privilegiada de atuar politicamente. De maneira semelhante, a contínua expansão e banalização da matéria constitucional submetida ao reexame politicamente inspirado do legislativo - que, em última análise, já se insinua naturalmente no próprio horizonte da positivação do direito - contribui para uma perigosa “desdiferenciação” entre direito e política.

No presente ensaio, direcionaremos nosso foco de análise para um problema associado no mais das vezes aos países em vias de desenvolvimento, e que alguns designam como “constitucionalização simbólica” (Marcelo Neves), isto é, a utilização da constituição como "instrumento de política simbólica”. ${ }^{9}$ [1] Nosso propósito é, tomando como contraponto a tese da "constituição como simulacro" ${ }^{10}$ (Luiz Moreira) [2],

come acquisizione evolutiva, op. cit., pp. 85-6.

8 „Über Verfassungen erreicht man also durch Beschränkung der Berührungszonen auf beiden Seiten eine immense Zunahme von wechselseitiger Irritabilität - mehr Möglichkeiten des Rechtssytems, politische Entscheidungen in Rechtsform zu registrieren, aber auch mehr Möglichkeiten der Politik, das Recht zur Politkumsetzung zu benitzen”, diz Luhmann, em Das Recht der Gesellschaft, op. cit., p. 471.

${ }^{9}$ Id., p. 478 (referindo-se a NEVES, Marcelo. Symbolische Konstitutionalisierung. Berlin: Dunker \& Humblot, 1998).

${ }^{10}$ MOREIRA, Luiz. A Constituição como Simulacro. Rio de Janeiro: Lumen Juris, 2007. Sobre as co-implicações desta com a tese de NEVES, consultar adiante, ponto 3. 
questionar se o sistema jurídico-constitucional brasileiro, por força de suas inconsistências, deve ser percebido como evidência de uma "modernidade periférica” ou não plenamente desenvolvida, ou, ao contrário, se tais infirmezas simplesmente repercutem problemas gerais do constitucionalismo, contradições intrínsecas, paradoxos - mesmo que agudizados, no contexto, pelo fato de ainda persistir, em nível institucional, um grau considerável de abertura do direito à influência não autorizada da política e de outras forças sociais [3].

Independentemente da resposta, a hipótese a ser avançada tem que a debilidade das normas constitucionais no Brasil, refletida na incessante lamentação pela sua ineficácia e na intensa atividade de reformulação a que são constantemente submetidas, está relacionada a condições estruturais da sociedade só indiretamente "manipuláveis" por meio dos instrumentos convencionais da política e do direito, muito embora o aprimoramento destes possa surtir - e não raro surta - efeitos indutivos mais ou menos controlados, dentro de um espectro de possibilidades amplamente variável. ${ }^{11}$ Como conseqüência, as conclusões a que chegarmos devem indicar, por via transversa, de que maneira se deve compreender a interferência de “elementos pré-modernos” na confecção da realidade normativa da sociedade atual.

1. Primeiro, um esclarecimento sobre o que vem a ser constitucionalidade simbólica, instrumento de uma política da mesma natureza, ${ }^{12}$ se faz necessário sobretudo para que não confundamos a circunstância assim designada com aquela que tinham em mente autores da primeira metade do séc. XX, ao falarem de “constituições de Terceiro Mundo" e seu caráter meramente nominal. ${ }^{13}$

Em síntese, podemos afirmar que uma constituição de viés simbólico nada mais é que um despistamento: sob a sua capa, o sistema político simula reações deflagradas pela observância das normas jurídicas (p. ex., recorrendo à noção de limites materiais à ação revisora do legislativo no terreno constitucional, ou ainda às possibilidades latentes de uma "mutação constitucional” juridicamente autorizada) apenas para restringir a verdadeira discussão política ao círculo de "especialistas" e profissionais da área. Não se trata, porém, de uma utilização estratégica da idéia de constituição, quer dizer, de uma ação coletiva orquestrada e devidamente adaptada à realização de uma determinada agenda ideológica, sob a batuta de elites interessadas na manutenção de uma "cortina de fumaça” entre elas e a opinião pública. É claro que esta afirmação

\footnotetext{
${ }^{11}$ Em outras palavras, reconhece-se o sentido de "planificação” que o direito positivo assume, sem com isso elidir a "cegueira" do curso evolutivo, que não necessariamente se orienta pela racionalidade imprimida pelos atos normativos individualmente considerados. Assim, v.g., a alteração da alíquota de um determinado imposto, de sua base ou de seus sujeitos passivos pode deflagrar resultados compatíveis com os objetivos de uma determinada política econômica ou de metas fiscais, mas não por isso é capaz de garantir por si só, ainda que usada de forma judiciosa, o sucesso geral de qualquer plano de reforma tributária.

12 Já que, para NEVES, devemos compreender "Symbolische Konstitutionalisierung als Überordnung der Politik über das Recht” - e, correspondentemente, como uma submissão da legislação simbólica a uma política simbólica. Op. cit., p. 122 e ss.

${ }^{13}$ Cf, a respeito, MÜLLER, Friedrich, Legitimidade como Conflito Concreto do Direito Positivo, in Cadernos da Escola do Legislativo, Belo Horizonte, 5(9), pp. 7-37, jul./dez. 1999. Paolo BISCARETTI DI RUFFIA e Karl LOEWENSTEIN estão entre os que pretenderam criar uma categoria própria para as constituições do "Terceiro Mundo".
} 
não abole o cálculo político no embate de forças travado entre os detentores imediatos do poder - e, por conseguinte, não torna possível negarem-se, como realidades verificáveis, a manipulação preordenada da comunicação de massas com fins políticoeleitorais, a expansão escandalosa de interesses corporativos velados na condução dos negócios do Estado, e mesmo o emprego meramente cosmético das constituições por regimes francamente autocráticos. No entanto, a idéia de um uso exclusiva ou precipuamente simbólico das constituições não pode ser reduzida à condição de um expediente mais ou menos manejável pelos grupos dominantes, ou seja, à mera instrumentalidade; é preciso levar adequadamente em conta a extrema complexidade de relações sociais que não se deixam determinar pela mera articulação planejada de manobras políticas visando a perpetuação ou o desmonte de um certo arranjo de poder. ${ }^{14}$

Marcelo Neves, para chegar à sua noção de constitucionalidade simbólica, estuda preliminarmente o que denomina legislação simbólica (symbolischen Gesetzgebung), apontando suas diferenças relativamente à política simbólica e ao direito concebido como estrutura simbólica. Para ele, mesmo que aceitássemos uma conceituação instrumental da legislação - decorrente de uma certa noção instrumental do direito positivo -, não por isso deveríamos acreditar que o problema da legislação simbólica se resume apenas à eficácia ou ineficácia das normas jurídicas, na medida que "em um sentido amplo, é possível sustentar que um número considerável de leis desempenha funções sociais latentes em contradição com sua eficácia jurídico-normativa, quer dizer, contrariamente ao seu sentido jurídico manifesto." 15 Assim, ele procede inicialmente a uma definição negativa, separando a legislação simbólica em si mesma da política simbólica (Murray Edelman), cuja função é condensar abstrações com a finalidade de apascentar o público de espectadores; do "direito simbólico" (T. W. Arnold), com seu sentido onírico e "conformador"; e também de mitologias e ritualismos políticos diversos.

Com efeito, Neves não só rejeita a idéia de que a legislação simbólica possa se confundir com quaisquer daqueles outros conceitos aludidos, como também recusa sua explicação fundada na distinção que opõe o ato de produção normativa ao texto assim produzido, negando estar a legislação simbólica referida à atividade produtiva, e não à lei. Segundo ele, no domínio da legislação simbólica, os significados estritamente jurídicos tanto do ato de produção legislativa quanto do seu resultado textual são como que içados por figuras políticas hiperbólicas e cambiantes. ${ }^{16}$ Do mesmo modo, Neves repele a diferenciação entre legislação simbólica e legislação instrumental, que se baseia na oposição correspondente entre a não-intencionalidade

\footnotetext{
${ }^{14}$ Em consonância com o postulado de que, em uma sociedade funcionalmente diferenciada, a idéia de um ápice ou de um centro da ação social esvazia-se por completo. Não é factível sustentar que um determinado grupo de pessoas, estribado no poder político e econômico, manipulam com sucesso o processo de construção social da causalidade de acordo com metas pré-determinadas.

${ }^{15}$ NEVES, Marcelo. Symbolische Konstitutionalisierung, op. cit., p. 33. Citando Joseph GUSFIELD, ele acrescenta: "many laws are honoured as much in the breach as in performance".

${ }^{16}$ Id, p. 34: “o conceito de legislação simbólica deve se relacionar amplamente com a significação específica tanto dos atos de produção [normativa] quanto dos textos produzidos, no que revela o problema de que o significado político de ambos se faz valer de modo hipertrofiado contra seus significados jurídico-normativos aparentes.” [trad. livre].
} 
e a intencionalidade de sua efetivação, de vez que produção legislativa há que se orientar preordenadamente, mas cumpre um papel simbólico notável.

Ao fim da série de negações, entretanto, conclui:

"Tendo em vista de que a atividade legislativa constitui um momento de confluência concentrada entre os sistemas da política e do direito, define-se a legislação simbólica como a produção de textos cuja conexão manifesta com a realidade é de caráter jurídico-normativo, embora, na verdade, sirva primária e hipertroficamente a objetivos políticos que não apresentam características jurídico-normativas específicas."17 [ênfase adicionada]

Assim esboçada, a symbolische Gesetzgebung não possui a conotação de algo positivo ou, contrariamente, de algo negativo, indicando antes uma dimensão da atividade legislativa que se verifica nos vários campos específicos do sistema jurídico, de modo difuso. A constitucionalização simbólica, a seu turno, atinge o núcleo sistêmico do direito: sua relação especial com o sistema da política - em vista de que se condicionam as alterações legislativas válidas a um processo político que apareça como adequado às prescrições normativas do direito constitucional - e seu modo de operação binário - pelo qual se engendra a sombra da inconstitucionalidade (um direito que não está de acordo com o direito!), com todas os seus reflexos jurídicos e correlativas possibilidades de emprego estratégico por uma política instrumental/simbólica. Por isso mesmo busca Marcelo Neves ulteriormente "distinguir com nitidez entre a função simbólica das 'constituições normativas' na Europa Ocidental e na América do Norte e a 'constitucionalização simbólica'," que “põe em questão a funcionalidade e autonomia do direito positivo estatal como um todo."18 Levando essa dicotomia às suas últimas conseqüências, poderíamos dizer que os chamados "efeitos simbólicos da constituição normativa” teriam mais a ver com a legislação simbólica, sendo como que o verdadeiro lado positivo da constitucionalização simbólica propriamente dita, cujo "lado positivo" surge - seja na forma de reverência retórica a valores tais como democracia e paz, seja como propaganda externa - sempre atrelado ao aspecto negativo de indicar baixa capacidade de produzir a generalização congruente de expectativas normativas. ${ }^{19}$

A constitucionalização simbólica, portanto, implica um efeito ilusório, que é o efeito ideológico, na acepção de Habermas. ${ }^{20}$ Cria-se dessa forma um modelo constitucional cuja implementação concreta somente seria possível sob condições sociais completamente diferentes, com o qual se tira de vista o fato de que as situações sociais correspondentes a tal modelo só poderiam ser realizadas por meio de uma transformação revolucionária da sociedade, ao mesmo tempo em que se mascara

\footnotetext{
${ }^{17}$ Id., pp. 33-4 [trad. livre].

${ }^{18}$ Id., p. 86 [trad. livre].

${ }^{19}$ Id., pp. 83-4, em capítulo intitulado "Constitucionalização Simbólica em Sentido Positivo: Função Político-Ideológica da Atividade Constituinte (Verfassunggebung) e do Texto Constitucional” (citando Brun-Otto BRYDE, Verfassungentwicklung: Stabilität und Dynamik im Verfassungsrecht der Bundesrepublik Deutschland. Baden-Baden: Nomos, 1982.).

${ }^{20}$ Ou seja, ,Illusionen, die mit der Macht gemeinsamer Überzeugungen ausgestattet sind, nennen wir ja Ideologien.” Cf. id., p. 84 (citando HABERMAS, Jürgen. Hannah Arendts Begriff der Macht, in Philosophischpolitische Profile. Frankfurt am Main: Suhrkamp, 1987, p. 246.).
} 
(e justifica) a perpetuação dos privilegiados “donos do poder” com um discurso apologético sobre as intenções dos "pais fundadores", identificadas às dos governantes do momento.

Esta caracterização, contudo, ainda está incompleta se não se faz referência ao quadro sociológico de alopoiesis do direito que acompanha, ou melhor, que perfaz o cenário em que se desenvolve o fenômeno da constitucionalização simbólica. O afã de estremar as "constituições normativas" daquelas carentes de tal energia vinculativa impele a que se digam as razões por que estas últimas seriam encontradas mormente em países ditos de "modernidade periférica”. Para Marcelo Neves, a observação dos problemas da reprodução do sistema normativo em tais países revela um bloqueio em sua operação autônoma, devido a uma vasta gama de fatores sociais que levam a uma precedência dos códigos econômico e político sobre o código do direito, consubstanciada nas distorções provocadas pela subintegração/sobreintegração no sistema jurídico. ${ }^{21}$ Esta criação heterônoma (állos = outro; poiesis = criação, produção) se mostra como sintoma de um sistema incapaz de "traduzir" as intercorrências do meio como acontecimentos internos, isto é, sem “filtros” para mediar a pressão direta dos influxos externos.

Neves, portanto, descreve um fenômeno distinto da corrupção sistêmica, que é localizada: a alopoiesis do direito generaliza uma degradação que já não mais cede a auto-imunizações. Ademais, ele coloca em xeque, no plano empírico, o próprio conceito de autopoiesis do direito, que se desvestiria de qualquer plausibilidade concreta na maioria dos países, assumindo, sob sua lente, tonalidades normativas. A generalização das relações de subintegração e sobreintegração impõe uma estrutura hierárquica às relações sociais, que assim ficam ancoradas a padrões pré-modernos e deixam de prover um ambiente favorável a que a constituição promova o acoplamento estrutural da política e do direito.

2. Numa outra aproximação do problema, calcada em pressupostos históricofilosóficos hauridos do tesouro da tradicional linhagem européia ocidental, Luiz Moreira denuncia, como já assinalamos, a constituição como simulacro. A familiaridade da semântica empregada e a relativa economia do argumento, porém, não logram esconder a iconoclastia dos resultados obtidos com o radical desmonte, empreendido pelo autor, do aparato legitimador que sustenta o constitucionalismo como um todo.

Moreira, na esteira de um certo hegelianismo, ${ }^{22}$ concebe o direito como reciprocidade da liberdade, para demonstrar, por uma tripla análise política, religiosa e econômica, que

"Vínculo político-jurídico, titularidade de direitos e co-autoria da ordem jurídica

${ }^{21}$ Cf. a respeito Neves, Marcelo. Entre Subintegração e Sobreintegração: A Cidadania Inexistente, in DADOS Revista de Ciências Sociais, vol. 37, n. ${ }^{\circ}$ 2. Rio de Janeiro: IUPERJ; especificamente sobre seus efeitos constitucionais, id., Verfassung und Positivität des Rechts in der peripheren Moderne. Eine teoretische Betrachtung und eine Interpretation des Falls Brasilien. Berlin: Dunker \& Humblot, 1992, p. 94 e ss.

${ }^{22}$ Próximo, em minha opinião, ao propugnado por Axel HoNNETH, com seu viés intersubjetivista-comunicativo e gramatical-normativo. Cf. Justiça e Liberdade Comunicativa: Reflexões em Conexão com Hegel, in Revista Brasileira de Estudos Políticos, n. ${ }^{\circ}$ 89, 2004; id., The Struggle for Recognition - The Moral Grammar of Social Conflicts. Cambridge: The MIT Press, 1996. 
estatal [...] são as especificidades que marcam a relação entre sujeitos de direito. Os direitos subjetivos implicam reciprocidade na articulação do conceito moderno de liberdade. Como são recíprocos, sua estrutura denota uma constituição intersubjetiva, pois somente em uma relação interpessoal se faz possível o reconhecimento da co-autoria do ordenamento jurídico, co-autores livres e iguais que concebem uma reciprocidade de direitos e obrigações comuns a todos os sujeitos de direito.”. ${ }^{23}$

Nessa trajetória, ele visita os alicerces da ética - a moderna mais pontualmente, confirmando a de Hegel sobre a de Kant; investiga as dificuldades da realização normativa da isonomia em um universo cultural polimórfico, acusando uma ostensiva "política de eliminação progressiva de estilos de vida distintos”, institucionalizada na burocracia e na economia capitalista; segue as transformações por que passa o direito, na reconstrução efetuada pela teoria discursiva do direito, de Habermas, corrigindo-a e expandindo-a com Lima Vaz; e discute particularidades do entramado normativo da moral e do direito, no caminho trilhado por Klaus Günther, dando por irrecusável o seu "princípio U”. ${ }^{24}$

Mais à frente, encarando o direito como ordenação, Moreira mostra como a centralidade do Estado na institucionalização da positividade das prescrições jurídicas se revela na capacidade de concatenar os recursos necessários para conferir legitimidade aos atos do soberano. Por meio da aglutinação de elementos simbólicos em torno do poder estatal, denotando unidade ao longo do tempo - um povo, sobre uma terra, com uma história sua -, concebe-se uma aparelhagem dotada de um repertório semântico capaz de produzir o sentimento de pertença e a prontidão para o sacrifício que exige o funcionamento internamente adequado do monopólio normativo. Sob a forma lógica do código, o direito, que constrange e direciona a força através dos meios organizacionais do Estado, faz as vezes de um catecismo secularizado, na medida em que se insere em um panorama de "osmose entre o aparato estatal e o universo simbólico e institucional da Igreja." ${ }^{25}$ É que, repelindo a tese defendida por Habermas de que "o direito moderno seria o herdeiro normativo de uma eticidade substancial em decomposição”, ${ }^{26}$ Luiz Moreira confirma que

"sua tensão constitutiva entre fato e norma, entre o caráter fático de sua obrigatoriedade e o caráter simbólico de sua legitimidade, decorre fundamentalmente da apropriação pelo Direito das teias prescritivas engendradas pela Igreja.,27

\footnotetext{
${ }^{23}$ MOREIRA, op. cit., pp. 1-2.

${ }^{24}$ Um ponto sensível da proposta de Moreira, pois a moral democrática moderna deve permanecer amplamente controversa, e sem repercussões jurídicas diretas, caso se pretenda refinar a sensibilidade moral e expurgar o moralismo da legislação.

${ }^{25}$ MOREIRA, op. cit., pp. 54-5. Com esse posicionamento, MOREIRA se insere em uma linhagem que vai de Ernst KANTOROWICZ a Paolo PRODI, passando por Carl SCHMITT, e que explora os sentidos histórico, filosófico e institucional da "sacralização" ou "eclesiasticismo" do Estado, fruto de uma "osmose entre o trono e o altar” (MOREIRA, op. cit., p. XIV). Cf. KANTOROWICZ, Ernst H. The King's Two Bodies: A Study in Medieval Political Theology, Princeton: PUP, 1997; SCHMITT, Carl. Teologia Política. Belo Horizonte: Del Rey, 2006 (contendo os estudos de 1922 e 1970); PRODI, Paolo. Il sacramento del potere. Il giuramento politico nella storia constituzionale dell'Occidente. Bolonia: Il Mulino, 1992; e LENHARO, Alcir. Sacralização da Política, 2. ed. Campinas: Papirus, 1986 (debruçando-se especificamente sobre o Brasil dos anos 30).

${ }^{26}$ MOREIRA, op. cit., p. 55.

${ }^{27}$ MOREIRA, op. cit., p. 74
} 
Aqui se alcança uma altura crítica no arrazoado de Moreira. Para justificar a tese da osmose, ele aduz como argumento que tal apropriação se deu principalmente como assimilação do confessionário, cuja estrutura propiciaria nas consciências a introjeção de normas externas, dando-lhes "unidade prescritiva.” Sob este olhar, não houve ruptura entre clero e potestade, mas uma "metamorfose nos padrões normativos", de que se origina a dupla dimensão fático-normativa do direito moderno. Entra em cena a consciência individual, exercendo um papel-chave, já que a osmose ocorre por meio da introjeção do aparato simbólico próprio à confissão, agora instrumento de intervenção no foro íntimo dos súditos, não mais dos crentes. Com isso se gera uma consciência da obrigatoriedade das normas validamente emanadas pela autoridade política, uma adesão consentida ao poder normativo do Estado, que se efetiva por meio da pertença, ou seja, de um nexo histórico expresso simbolicamente que possibilita ao súdito ver-se como pessoalmente pertencente a uma instituição secular. Em resumo, “o sentimento de pertença inaugura o domínio da consciência,” e tem como corolário que a máxima instância do poder coincida com a reunião dessas consciências em um corpo político, representado juridicamente no constituinte originário.

Embora não fique totalmente claro como se pôde colocar em marcha uma dinâmica social que estimulou as individualidades a ter, a partir da Modernidade, uma maior predisposição à aquiescência racional sobre o fundamento das decisões normativas, ${ }^{28}$ o certo é que a solução achada para cimentar um patamar mínimo de consenso substantivo sobre premissas axiais de orientação jurídica do comportamento o erguimento de constituições - acaba por atribuir-se uma aceitabilidade intrínseca, a um tempo científica e dogmática. O credo constitucional ${ }^{29}$ epitoma, assim, uma extensa e gradual mutação, com a qual se promovem as simultâneas justificação e sacralização de uma normatividade jurídica assentada na universal reciprocidade da liberdade individual.

Mas como admitir que as amarras constitucionais estabelecidas imobilizem o contínuo fluxo comunicativo de uma sociedade constituída de cidadãos livres e iguais, cujos discursos são irremediavelmente marcados pela falibilidade, e, portanto, contingentes? É a essa dificuldade que se oferecerá a saída de qualificar a constituição como simulacro.

“Simulacro” não é só falso aspecto, aparência enganosa, imitação, arremedo ou parecença; um de seus sentidos, antigo e beirando o desuso, exprime também “representação de pessoa ou divindade pagã; ídolo, efígie” (Houaiss). Entronizada no panteão da democracia como fonte e medida da autoridade válida, essa deidade legalista

\footnotetext{
${ }^{28}$ E mesmo sua relevância, pois não custa lembrar que é no condicional que está aquele “poderiam” da fórmula de Habermas: „Gültig sind genau die Handlungsnormen, denen alle möglicherweise Betroffenen als Teilnehmer an rationalen Diskursen zustimmen könnten” [grifo meu]. A propósito, cf. a crítica de Niklas LuHMANN em Quod Omnes Tangit..., Anmerkungen zur Rechtstheorie von Jürgen Habermas, in Rechtshistorisches Journal, no. 12, 1993.

${ }^{29}$ Cf., p. ex., representando uma farta literatura, LEVINSON, Sanford. Constitutional Faith. Princeton: Princeton University Press, 1988; id., "The Constitution” in American Civil Religion, in The Supreme Court Review, 1979, pp. 123 a 151. MOREIRA (op. cit., p. 80) acresce: “A invocação da tutela constitucional garantiria a instauração do rito de passagem de uma esfera profana a uma esfera sacrossanta. Tal sacralidade fica ainda mais evidente na aura de intocabilidade, de ato fundador, de manancial que é conferida ao ato constituinte: fiat lux!”.
} 
se põe no lugar do povo soberano como Criador e criatura, fazendo convergir no ato constituinte a invenção da comunidade política pela lei e a invenção da lei pela comunidade política. Por uma habilíssima prestidigitação, a constitucionalização do Estado de direito re-introduz a unidade do evento fundador (a unidade da diferença entre obrigatoriedade e legitimidade) no lado da lei, dando azo a um legocentrismo que tem como pivô o texto constitucional. Envolto em uma aura mítica, o evento fundador, cujo signo-mor é a constituição, aciona a mecânica que permite à forma do direito tomar de empréstimo a convicção não confirmada de que um consenso político autêntico subsidia seu sentido. Não por acaso, pois, este paradoxo se desvenda na tautologia mencionada por Moreira: como é na constituição que se cirzem a validade política e o dever-ser imponível das leis que regem os homens, num governo em que estes devem obedecer àquelas, sua forma jurídica é a única capaz de produzir forma jurídica, já que tem imediata suposição de legitimidade e dá parâmetro para todo direito que se produz sob seu abrigo. ${ }^{30}$

Por não haver como confiar irrestritamente nessa suposição, dada sua ampla variabilidade no tempo, não é possível "transformar um consenso sobre a forma de constituir e ordenar o sistema jurídico, obtido em um dado momento histórico, em algo atemporal”, nem aceitar que um "ato de outorga que uma assembléia se dá a si mesma com o propósito de restringir, regular e prescrever os direitos atinentes à soberana manifestação dos sujeitos de direito" possa, sempre e independentemente de revisão das regras adotadas, justificar estas limitações. O embuste consiste em canonizar o poder constituinte, imputando-se-lhe a qualidade de matriz genética inquestionável do ordenamento e de suas instituições, que sub-roga a autodeterminação dos sujeitos de direitos, reciprocamente reconhecidos como livres. Nele caem não só as repúblicas “periféricas”, mas todo projeto de Estado constitucional democrático, em maior ou menor medida.

Democracia ou constitucionalismo; governo dos homens ou governo das leis; soberania popular ou direito positivo estatal legítimo: quem vem primeiro? Prevalece o poder supremo de quem "decide sobre o estado de exceção" ou a lei a que este se sujeita deliberadamente? Moreira, de sua parte, rompe honestamente o nó: reconhece a incompletude da soberania sem os direitos fundamentais, pois que restariam desguarnecidas e a descoberto a liberdade e a autonomia dos indivíduos, mas faz derivar a existência e a validade destes a partir do ato político fundamental de uma comunidade libertária e isonômica, de modo que "a ausência das normas resulta em perda, mas não na inexistência da disposição soberana dos sujeitos de direito." 31

${ }^{30}$ Cf. MOREIRA, op. cit., p. 86: "Essa tautologia tem o propósito de conferir validade ao processo legiferante, de modo a dotar-lhe da autorização para prescrever condutas independentemente da aferição entre o produzido e a manifesta autorização de vigência decorrente da soberania popular.” Em outras palavras: confere positividade ao direito. Sobre este tema $c f$. LUHMANN, Niklas. La Differenziazione del Diritto, Bologna: Il Mulino, 1990, p. 103 e ss. (A positividade do direito como pressuposto de uma sociedade moderna.); id., Sociologia do Direito II, Biblioteca Tempo Universitário. Rio de Janeiro: Tempo Brasileiro, 1985, p. 7 e ss. (Conceito e função da positividade).

${ }^{31}$ MOREIRA, op. cit., p. 98. Sobre esta tensão, mas defendendo a eqüiprimordialidade ou co-originalidade, não a precedência, $c f$. HABERMAS, Jürgen, Constitutional Democracy: A Paradoxical Union of Contradictory 
Como se extraem diretamente da fonte do poder constituinte originário, os direitos e garantias fundamentais não são obra da constituição, mas tão só reconhecidos por ela, pois, na verdade, "são postos pelo Direito, como disciplina ordenadora da liberdade” (os direitos são postos pelo Direito, que por sua vez é a normatividade que exsurge do universal reconhecimento da liberdade!). Daí procede que não há esfera jurídica fora do alcance da ação plenipotenciária dos sujeitos soberanos, os quais podem emanar tantos atos fundadores quantos quiserem, e que a constituição não abriga a "sede material de legitimidade das normas."

3. Ninguém duvida que as normas constitucionais de muitos países em vias de desenvolvimento carecem de efetividade e concretização, e que deixam de exprimir seu sentido cogente, como parte que são do direito positivo. Ninguém duvida também que o direito freqüentemente, em casos limite, se emprega como pura ferramenta do poder. À Constituição brasileira, mais precisamente, não se pouparam vitupérios e imprecações contra sua inópia, nem lhe faltaram réquiens. ${ }^{32}$ Repleta de normas programáticas e de direitos sociais que muitas vezes não passam de abstrações ideológicas jamais implementadas de forma enfática, essa Constituição parece se amoldar bem ao conceito de "constituição transicional” oferecido por Arthur Jacobson: "a constitution embodying, embracing, and propelling forward in the basic framework those political paradoxes which the great political forces are unable, for the moment, to resolve in permanent accomodations." 33 Em termos dogmáticos, tal estado de coisas é comumente descrito como um descompasso entre a constituição formal e a constituição material, provocado pela "inadequação do sistema político e da ordem jurídica ao atendimento das necessidades básicas da ordem social,” que faz com que a soberania popular esteja fadada a "tornar-se um mero símbolo formal, referendando (...) os conteúdos constitucionais de um outro poder constituinte, o das forças reais de poder (...). ${ }^{34 \text {, }}$

Principles?, in Political Theory, vol. 29, no. 6, 2001; id., Sobre a coesão interna entre Estado de direito e democracia, in A Inclusão do Outro. São Paulo: Loyola, 2002, p. 290 (esp. o item III, "Sobre a mediação entre soberania popular e direitos humanos”); id., Direito e Democracia: entre facticidade e validade, tomo I. Rio de Janeiro: Tempo Brasileiro, 1997 (em particular a primeira parte do cap. 3).

${ }^{32}$ V., p. ex., STRECK, Lênio Luiz. Os Meios e Acesso do Cidadão à Jurisdição Constitucional, a Argüição de Descumprimento de Preceito Fundamental e a Crise de Efetividade da Constituição Brasileira, in Sampaio, José Adércio Leite e Cruz, Álvaro Ricardo de Souza (orgs.), Hermenêutica e Jurisdição Constitucional. Belo Horizonte: Del Rey, 2001, p. 250-51; MEIRELLES, Hely Lopes. Direito Administrativo Brasileiro, 24. ed. São Paulo: Malheiros, 1999, p. 57; BASTOS, Celso Ribeiro. Direitos e Garantias Individuais, in CRETELLA JR., José; MARTINS, Ives Gandra da Silva; e REZEK, Francisco (eds.), A Constituição Brasileira de 1988: Interpretações. Rio de Janeiro: Forense, 1988, p. 27; para a visão de um brasilianista, cf. ROSENN, Keith S. Brazil's New Constitution: An Exercise in Transient Constitutionalism for a Trasitional Society, in The American Journal of Comparative Law, vol. 38, 1990, p. 773 a 802: "If there were any truth to the old canard that a camel is a horse drafted by a committee, the new Brazilian Constitution would resemble a hydra-headed Pegasus. [...] Brazil's long awaited Constitution is a lengthy, detailed and convoluted document [...]. The drafters obviously ignored the wisdom in John Marshall's celebrated dictum in McCulloch v. Maryland (defendendo o minimalismo constitucional).”

${ }^{33}$ JACOBSON, Arthur. Transitional Constitutions, in Cardozo Law Review, vol. 14, 1993, p. 947.

${ }^{34}$ Cf. BERCOVICI, Gilberto. O Poder Constituinte do Povo no Brasil: Um Roteiro de Pesquisa sobre a Crise Constituinte, in Lua Nova - Revista de Cultura e Política n ${ }^{\circ}$ 61, São Paulo, CEDEC, 2004, pp. 5-24 (apoiando-se em Paulo BONAVIDES). 
O tema, entretanto, desborda os lindes do constitucionalismo. Não faltam, na literatura sócio-antropológica, histórica e política brasileira, análises, diagnósticos, proposições teóricas com as quais se busca fornecer uma interpretação e apontar vias para uma intervenção nas condições sociais desvantajosas que supostamente bloqueiam o pleno desenvolvimento de nossa democracia. De Oliveira Vianna a Darcy Ribeiro, de Euclides da Cunha a Gilberto Freyre, numa trilha que passa por Raymundo Faoro, Sérgio Buarque de Hollanda e José Murilo de Carvalho, a reflexão nacional sobre o ‘caso brasileiro' produziu diversos clássicos e uma imensa bibliografia, na qual a condição subdesenvolvida é um fator recorrente, quase onipresente. Tais exames detectam, na composição do quadro, elementos de monarquismo clássico, paternalismo político, escravismo, patrimonialismo, familismo, catolicismo e retoricismo, entre outros, tendo já se acrescido a essa receita, sob a sombra do darwinismo social, os predicados e atavismos do homem considerado como raça. Algumas 'explicações' redundaram em lugares-comuns, como os que se associam à trilogia samba-futebol-carnaval, ou a supostos vícios hereditários, advindos de um tempo em que para o Brasil se baniam degredados e criminosos perigosos. No geral, predomina a impressão de que o "homem cordial”, “cidadão inativo” que é, carrega as marcas psicológicas de uma promiscuidade originária que desfez as fronteiras entre lei e transgressão, entre coisa pública e vida privada, obliterando seu acesso à civilidade.

$\mathrm{Na}$ história recente do Brasil, e desde que se começou a retomar o caminho da normalidade constitucional, o antigo problema da "identidade nacional" - que passou a ser uma preocupação para as classes dominantes na época em que a abolição da escravatura se afigurou iminente, e que se fixou a partir de então como o pano de fundo contra o qual se desenrolaram os subseqüentes debates acerca do modelo de república a ser erigida - parece ter-se convertido na sôfrega busca por uma forma de estabelecer os vínculos éticos que hipoteticamente garantiriam o funcionamento adequado do Estado, imunizando-o contra a tentação sempre presente de se prestar a ser meio de obtenção de privilégios e garantidor do status quo. Aliás, não à toa a literatura brasileira sobre "moralidade administrativa", principalmente por força de sua inscrição como princípio constitucional, cresceu exponencialmente. Tudo leva a crer que a semântica tradicional da identidade coletiva, transmudada no discurso da "ética na política”, ${ }^{35}$ mascara precisamente aquilo que quer demonstrar: as condições sociais de realização de um direito positivo limitado politicamente, e de uma política institucionalizada limitada juridicamente, através da constituição.

Tudo isso pode nos estimular a perguntar, mais uma vez, se a Constituição que temos não é tão somente um espelho em que miramos nossa verdadeira constituição corrompida.

\footnotetext{
${ }^{35}$ Esta passagem, porém, não deve ser interpretada como a transição de um dilema filosófico-antropológicocultural para outro, de natureza pragmática e institucional - até mesmo porque uma visão retrospectiva sobre o desenvolvimento das idéias políticas e sócio-antropológicas no Brasil evidencia o predomínio e a ascendência da reflexão em torno da "organização do poder" e da viabilidade das instituições. Cf. CARVALHO, José Murilo de. Entre a Liberdade dos Antigos e a dos Modernos: A República no Brasil, in Pontos e Bordados: Escritos de História e Política. Belo Horizonte: Editora UFMG, 1999, especialmente pp. 101-02. Essa insistência sobre “questões orgânicas”, diga-se de passagem, não pode ser identificada ao repertório temático tradicional do pensamento democrático, como acertadamente aponta Andreas KALYVAS em Carl Schmitt and the Three Moments of Democracy, in Cardozo Law Review, vol. 21, 2000, p. 1527.
} 
E a resposta é não, se pensamos que o projeto constitucional serve também para alavancar transformações desejadas nas condições objetivas de vida; ou sim, se por ela medimos o grau em que nos desviamos, na prática, de suas determinações. Da mesma forma, e pelas mesmas razões, podemos dizer que a Constituição é uma farsa e não é: que escamoteia, sim, a ambígua autoridade/violência que afirma de si a própria legitimidade, ${ }^{36}$ mas que é autêntica como limitação auto-imposta de um poder ilimitado por definição. Nisso, modernos e não-modernos se equiparam. Aqui ou lá, a constitucionalidade de um ordenamento jusnormativo, ou melhor, as qualidades epistêmicas dos procedimentos do Estado constitucional democrático, não são bastantes em si mesmas para garantir a institucionalização progressiva de iguais direitos, mas apenas para, "na melhor das hipóteses, oferecer uma boa probabilidade de sucesso.”37 Lá ou aqui, o décimo segundo camelo da história seria $e$ não seria necessário. ${ }^{38} \mathrm{E}$ em tempos em que as "condições econômicas e sociais privilegiadas do pós-guerra”39 para os países da OCDE cedem lugar a uma economicização mundializada que corrói as bases do Estado de bem-estar, sem colocar em seu lugar nenhuma opção viável de inclusão, a sombra da "brasilianização" dos sistemas constitucionais ameaça avançar rapidamente sobre a modernidade central. ${ }^{40}$

Resta então saber como podemos, diante do convencimento da existência de uma sociedade do mundo, tratar a diferenciação entre centro e periferia (e assim entre sistemas constitucionais de centro e de periferia) num contexto em que um e outra podem estar virtualmente em qualquer lugar [A]. E mais: quer a constitucionalização simbólica seja apanágio dos países de 'modernidade periférica', quer prepondere a visão mais visceral do fenômeno constitucional como simulacro, é preciso de qualquer jeito responder à pergunta sobre como se pode sobrepor um certo conteúdo jurídico às deliberações do soberano, seja como meio de defesa de minorias, seja como 'cláusulas pétreas' onde se ancora um compromisso maior que a vida, seja ainda como direito de resistência (por motivos políticos, de consciência ou de crença) [B].

A. Somente quando se toma como ponto de partida a existência de um sistema da sociedade mundial é que se pode explicar porque até hoje existem diferenciações regionais - não apenas as sociedades tribais arcaicas que resistem - onde a tessitura comunicacional da sociedade não assume a forma de diferenciação sistêmica. Tais "regionalismos" se explicam como diferença entre uma participação nas estruturas dominantes da sociedade mundial e uma reação contra elas, que se realizam em proporções as mais variadas, de lugar para lugar. Assim, mesmo a invenção/reconstrução

${ }^{36}$ Para uma 'desconstrução' da ambivalência essencial do termo alemão Gewalt, tomando por mote o Zur Kritik der Gewalt, de Walter BENJAMIN, cf. DERRIDA, Jacques, Force of Law: "The Mystrical Foundation of Authority", in CARSON, David Gray; CORNELL, Drucilla e ROSENFELD, Michel (eds.), Deconstruction and the Possibility of Justice. New York: Routlege, 1992.

${ }^{37}$ HABERMAS, Jürgen. Caminhos da Destrancendentalização: De Kant a Hegel e de Volta, in Verdade e Justificação. São Paulo: Edições Loyola, 2004, p. 222.

${ }^{38}$ Cf, LUHMANN, Niklas. A Restituição do Décimo Segundo Camelo: Do Sentido de uma Análise Sociológica do Direito, in ARNAUD, André-Jean e LOPES JR., Dalmir (orgs.), Niklas Luhmann: Do Sistema Social à Sociologia Jurídica. Rio de Janeiro: Lumen Juris, 2004, p. 34.

${ }^{39}$ HABERMAS, Jürgen. Caminhos da Destrancendentalização, op. cit., p. 222

${ }^{40}$ Vide NEVES, Marcelo. Symbolische Konstitutionalisierung, op. cit., p. 156. 
de 'tradições próprias' acaba sendo um fenômeno da sociedade mundial, de reação às possibilidades de comparação abertas com a modernidade.

Mas os fundamentos da diferença entre países centrais e países periféricos são econômicos. Na medida em que a modernização progride no sentido de uma diversificação das necessidades, as regiões se tornam dependentes do sistema econômico mundial em vários aspectos, como produção, venda e crédito. Uma vez postos em contato com as estruturas locais, os sistemas funcionais afetam os modos de seleção racional, reforçando discrepâncias: quem tem mais patrimônio ou renda consegue crédito mais fácil; quem tem acesso a mais possibilidades de informação atualizada, também pode levar a cabo as melhores pesquisas e se manter à frente dos que dependem de conhecimento de segunda mão, etc. O bias econômico, então, gera um modelo centro/periferia, não necessariamente estável, mas cujos centros de gravidade podem ser rastreados.

Todavia, não há como manter o forte contraste entre sociedades tradicionais e modernas. Várias são as circunstâncias sob as quais as estruturas tradicionais, na transição para a sociedade moderna, produziram efeitos favoráveis (a própria osmose a que alude Moreira). A sociedade mundial, digamos, 'beatifica' aquilo que na tradição lhe é propício. Por isso dificilmente se encontra ainda uma ordem de vida absolutamente autóctone, mas antes circunstâncias que resultam do cruzamento das vantagens estruturais e operações da sociedade mundial, com condições especiais, culturais, regionais, geograficamente delimitadas. Com a adaptação do grau de desenvolvimento da sociedade mundial por meio de uma industrialização politicamente induzida, junto da urbanização que a acompanha, abolem-se velhas estruturas estratificadas, de modo que a economia familiar de pequenos proprietários, na agricultura e na produção artesanal, se decompõe em peças intercambiáveis, dinheiro e mão-de-obra. Isso dá causa a uma marcada diferença entre exclusão e inclusão, com o respectivo empobrecimento de vastas parcelas da população, e a transformação do Estado em órgão de perpetuação dessa diferença, principalmente em virtude das políticas de desenvolvimento.

A diferença de inclusão e exclusão tem sérios efeitos, pois, por uma parte, ela é deflagrada pela diferenciação funcional da sociedade mundial, mas, por outra, dificulta, senão impede, a realização desta em nível regional. Ela impede o desenvolvimento de um mercado satisfatório, maior e mais diferenciado, pressuposto de uma produção em massa voltada para o mercado, fazendo com que os países periféricos se tornem, de certa forma, dependentes de exportações, e expondo suas economias a sérias oscilações. Ela leva a que, além do mais, grandes círculos da população não sejam incluídos no sistema do direito, de tal sorte que o código direito/não direito (ou jurídico/antijurídico) não se faz valer, ou se faz apenas de maneira muito reduzida.

Tudo isso está, como dissemos, profundamente ligado ao advento de uma sociedade moderna de abrangência mundial. As enormes diferenças de reprodução sócio-jurídica entre países desenvolvidos e subdesenvolvidos são, tudo somado, indicativas da presença de operações sistêmicas subjacentes, que perpassam e unificam a sociedade como universo total da comunicação. Mesmo a defesa de uma preservação da diversidade - cultural, ecológica - só adquire significação diante de uma ação contrária, unificante, e destaca o fato de que a lógica sistêmica da redução de complexidade se 
alimenta da complexidade. Centro e periferia, destarte, pressupõem-se mutuamente e estão co-implicados nos mesmos paradoxos. E mais: nada nos faz crer que os marcos em que estes se atualizam hão de permanecer os mesmos indefinidamente - muito pelo contrário! Marcelo Neves mesmo reconhece que

“os recentes desenvolvimentos da sociedade mundial apontam no sentido de uma mobilidade nas posições de centro e periferia, podendo-se observar também tendências a uma paradoxal periferização do centro"

embora daí não extraia uma conclusão pelo primado da diferenciação funcional e da reprodução autopoiética, auto-referencial da sociedade e seus subsistemas.

Não parece de forma alguma desprezível o conjunto de observações que sinaliza essa periferização do centro. Mas mais que inventariar as distorções que invertem a dinâmica entre centro e periferia, convém dimensionarmos a alegada ruptura do fechamento operativo do direito no Brasil. Se não se pode negar que o canteiro de obras em que se converteu a experiência constitucional brasileira encerra uma longa coleção de "promessas não cumpridas", ${ }^{41}$ agravadas pelo fato de a autonomia da política ser generalizadamente solapada por intromissões espúrias advindas de seu ambiente imediato, disto não segue que o próprio direito não tenha tomado a forma de direito positivo, e que assim não cumpra o papel que lhe é reservado na modernidade.

A positividade é apontada de modo quase unânime como uma das principais qualidades distintivas do direito moderno, ou seja, do direito de uma sociedade diferenciada funcionalmente. Mesmo para os que defendem que a legitimidade de todo direito reside na possibilidade de um acordo racional-comunicativo sobre os procedimentos de sua formulação, a positividade é tida como um fator decisivo para a relevância social do direito em um quadro de dissolução das hierarquias tradicionais. ${ }^{42}$ “A positividade do direito significa que, com uma estrutura normativa conscientemente posta em vigor, surge um nível artificialmente produzido de realidade social que existe apenas enquanto não é revogado, uma vez que cada um de seus componentes individuais pode ser modificado ou tornado sem validade.” ${ }^{\text {,3 }}$ Em outras palavras, positividade significa a apropriação reflexiva da consciência da precariedade das estruturas normativas do direito, tendo como resultado que a atribuição de vigência aos comandos legais deve poder ser referida a uma decisão. Isso não implica a troca do conceito de "fonte" pelo de decisão, como ponto de onde o direito deriva geneticamente, mas sim que as mudanças legislativas já não mais se orientam pela distinção entre um direito eterno e outro mutável, entre um direito natural/racional e outro situado na esfera do poder do príncipe: a novidade introduzida com a positivação do direito traduz-se na legalização de sua seletividade estrutural.

A constituição, em suma, substitui a lei divina como lastro da irrevogabilidade do direito. Para que a constituição funcione como fecho do sistema do direito, facilitando a

${ }^{41}$ BOBBIO, Norberto. O Futuro da Democracia. Uma Defesa das Regras do Jogo, 5. ed. São Paulo: Paz e Terra, 1992, pp. 21-22.

${ }^{42}$ Cf. HABERMAS, Jürgen. Introduction, in Ratio Juris, vol. 12 nº 4, 1999, p. 330 (uma síntese dos principais argumentos desenvolvidos na obra Faktizität und Geltung a favor de uma teoria discursivo-procedimental do direito).

${ }^{43}$ HABERMAS, Jürgen. Direito e Democracia: entre facticidade e validade, op. cit., p. 60. 
aplicação reflexiva do código deste a si mesmo, basta que ela dissimule a crueza de um direito referido unicamente a si mesmo. Ela provê o filtro processual através do qual se selecionam alternativas retiradas do universo das projeções normativas disponíveis, dignificando simbolicamente as escolhas com a estampa da democracia. Isso a Constituição do Brasil faz, como fazem outras constituições democráticas de países em desenvolvimento, embora em intensidades variáveis. ${ }^{44}$ A frustração por sua deficiência em concretizar-se integralmente, em guiar-se por uma "preferência pela inclusão”, não elide o fato de que a comunicação que nela se estrutura juridicamente habilita de modo consistente a prática corriqueira de inúmeras atividades que a pressupõem: a defesa de situações jurídicas subjetivas especialmente protegidas; a formação (jurídica) de entidades familiares e a sucessão hereditária de bens; a proposição de ações que efetivam garantias constitucionais; a condução básica dos afazeres administrativos do Estado etc., tudo em referência direta à Constituição.

Ao que se nos afigura, os elevados índices de corrupção, ineficiência, impunidade e exclusão que, combinados, marcam a práxis do Estado de Direito brasileiro, não são suficientes para fazer inferir a inexistência de um direito positivo moderno ou o império da anomia, conseqüências últimas da constitucionalização simbólica. A nova dialética do senhor e do escravo que leva sintomas da periferia para o centro, também traz os do centro para a periferia, e faz uma ponte, embora não preencha o fosso. E se não é plausível abdicar do conceito de modernidade periférica, por ser de fato um conceito analiticamente muito profícuo, é pelo menos aconselhável rever os seus contornos no que concerne à substituição completa da reprodução autoreferida por um modelo alopoiético. É preciso, quiçá, uma visão mais dégradé.

B. Tanto Moreira quanto Neves se movimentam no terreno dos efeitos ilusórios práticos da constitucionalização do direito. Moreira, contudo, insiste em nos remeter para o fato de que não existe o certo acima do certo e do errado, de que não há uma regra superior, um supra direito, que há simplesmente o poder de sujeitos titulares de direitos, vinculados entre si política e juridicamente, e que constroem coletivamente o Estado - isto é, que há Gewalt. O simulacro denunciado, que é a vigência da constituição por força da própria constituição, ${ }^{45}$ subtraindo-se à ação subseqüente do "poder constituinte derivado" e pondo de lado a regra segundo a qual lex posteriori derrogat lege priori, faz saltar aos olhos o não-lugar encravado entre a justiça e a força.

Luiz Moreira, ao acender sua lanterna sobre o mimetismo que permitiu ao Estado moderno reproduzir o sagrado como secular, revela transparentes as vestes constitucionais com que se cobre a “vida nua”. É óbvio que com isso ele não se desfaz da herança liberal dos direitos individuais; mas conceder preeminência à democracia tem um custo. Torna-se agora imprescindível também superar a objeção de que o avanço para uma subordinação recursiva do poder ao poder e para a inclusão do público na

\footnotetext{
${ }^{44}$ Constituições normativas e constituições simbólicas, aliás, não fazem uma dicotomia, mas antes dois extremos de uma escala com muitas gradações, como diz o próprio Marcelo NEVES (Symbolische Konstitutionalisierung, op. cit., p. 83) - o que nos compele a buscar saber quais constituições ocupariam os pólos e como seria a distribuição dos casos nessa escala.

${ }^{45}$ Pois é ela que declara a soberania do povo, como se vê na CFB, art. $1^{\circ}$, parágrafo único.
} 
diferenciação do sistema político demanda regras fora do alcance dos participantes do jogo, meios cogentes de organizar o controle sobre o uso arbitrário da autoridade política.

A elusividade do problema de saber como as constituições podem reclamar para si um grau variável de imutabilidade, i.e., uma atrelagem a pontos considerados essenciais e intangíveis, ${ }^{46}$ remete-nos àquelas dificuldades de justificação de um direito plenamente positivado, transformado em uma estrutura cambiável. Da mesma forma que o direito positivo - na medida em que já não pode mais ser "simplesmente idêntico à totalidade das expectativas normativas congruentemente generalizadas" passa a exigir uma nova caracterização de sua identidade consigo mesmo que rompa com (= desdobre) a tautologia exposta pela evolução e resolva (=invisibilize) o caso de sua fundação, a constituição, que é exatamente o meio de operar esse fechamento, também requer um outro modo de manutenção da auto-referência, seja por meio da técnica do "cerne imutável”, seja pelo desenvolvimento de métodos científicos de resolução de controvérsias constitucionais (hermenêutica constitucional).

Este problema relaciona-se diretamente com as pretensões filosóficas de fornecer um ponto de apoio normativo transcendental para os princípios tidos como nucleares em um ordenamento jurídico-constitucional justo. Mas uma rota de acesso talvez mais vantajosa, na busca de uma compreensão esclarecida, está no rechaço à acusação de que a autonomização funcional-operativa do direito expõe a índole arbitrária do direito positivo, e no reconhecimento dos direitos fundamentais como aquisição evolutiva.

O direito, como sistema comunicacional que se desenvolve no tempo, depende da reiteração, condensação e confirmação de seus significados. Com isso se "reduz o espectro da arbitrariedade da relação entre signo e significante," ou ainda se "reduz a contingência da limitação da contingência,"48 fixando-se limitações já provadas na utilização arbitrária dos signos. A estabilização representada por uma memória operativa e recursiva (jurisprudência, precedentes, doutrina, registros), por sua vez, faz surgir "tendências históricas que delimitam fortemente o espaço da variação". ${ }^{9}$ Em termos jurídicos isso significa que o direito é discricionariamente determinado, mas não discricionariamente determinável. ${ }^{50}$ Trata-se de um acontecimento interno, porém,

${ }^{46} C f$., para a questão do chamado "constitutional essentialism”, mas de uma perspectiva contratualista, MICHELMAN, Frank. Morality, Identity, and Constitutional Patriotism, in Ratio Juris, vol. 14, n 3, 2001, especialmente p. 259 e ss.

${ }^{47}$ Cf. LUHMANN, Niklas, Sociologia do Direito II, op. cit., p. 27. Isso é o mesmo que dizer "idêntico ao direito vigente num dado momento", o que também pode ser aceito por quem postula que o direito deve estar “ancorado” em algo que lhe é exterior, seja o conteúdo moral do imperativo categórico, seja a conformação de um acordo comunicativo garantido por normas procedimentais que traduzem uma "moralidade pós-convencional”. Ao que parece, Luhmann está se referindo ao fato de que a dissociação das funções do direito relativamente à moral, à ciência e à pedagogia impõe que o direito venha definido em termos funcionais, e não ontológicos - e não à idéia de que o direito “extrapola” para dentro de outros domínios onde igualmente se formulam expectativas de comportamento (ou inversamente).

${ }^{48}$ LUHMANN, Niklas. Das Recht der Gesellschaft, op. cit., p. 128.

${ }^{49}$ LUHMANN, Niklas e DE GIORGI, Raffaele. Teoria della Società. Milano: Franco Angeli, 1993, p. 30.

${ }^{50}$ LUHMANN, Niklas, Sociologia do Direito II, op. cit., p. 10. A velha divisão direito natural/direito positivo já deixava entrever que a arbitrariedade atribuída a este último se devia a que ele não se deixava reconduzir ao primeiro como fundamento seu, pois precisava ajustar-se aos tempos e às conjunturas - imperativo que lhe excluía justamente o componente arbitrário. 
constitucional, e não da incidência de metanormas. A única outra opção a esta normatividade primária é a barbárie.

Os direitos fundamentais, em certa medida, exteriorizam o sinal de validez do direito, assimetrizam-no, prendendo-se ao substrato da "humanidade" ou da "racionalidade.” Não por outro motivo os fundadores da República americana davam grande relevância à Constituição como instrumento de governo, que se punha à disposição de direitos individuais previamente declarados: a inclusão dos direitos fundamentais na constituição faria recair sobre eles a desconfiança de que não passavam de direito positivo, modificável, e entraria em choque com a interpretação tradicional que vê os limites constitucionais do Estado como fruto de um longo desenvolvimento histórico dos direitos individuais. Com a preponderância de um modelo que junta instrumento de governo e declaração de direitos, ficou clara a disposição autológica da constituição. De toda sorte, a soberania popular ainda costuma ser descrita dogmaticamente como corolário da universalização de direitos subjetivos básicos.

Luiz Moreira tem muitas justificativas para suspeitar que a sagração do poder constituinte visa apenas tornar aceitável a forma jurídica da idéia de que os mortos governam os vivos. ${ }^{51}$ Com sua opção por um radicalismo democrático, que exibe a potencialidade sempre atual de um "ato fundador", ele não consegue evitar a aporia de um poder ilimitado que só pode agir limitadamente, mas em compensação devolve-nos a consciência da improvável artificialidade - da fragilidade - dos arranjos com que se constrói socialmente a realidade. O simulacro constitucional não é vil nem benfazejo per se, mas cumpre, enquanto for sustentável, a indispensável tarefa de tornar visível o que não pode ser visto de outro modo: a unidade do sistema. Assim como a fulminante visão da glória de Deus só pode ser apreciada no Verbo feito carne, também o poder soberano do povo só pode ser apresentado, no presente estágio da evolução social, na constituição. E assim como a Divindade revelada só pode prometer uma chance de salvação aos que crêem, também as constituições só podem ser propícias aos que professam seu credo. ${ }^{52}$ Podem ser.

Não se cuida de retirar os entraves ao livre exercício do poder soberano democrático, para que este se equipare em efeitos ao poder soberano de países centrais - até porque não cabe falar em "soberania bloqueada”, geradora de permanente crise constituinte. ${ }^{53}$ As constrições endógenas são inafastáveis; as exógenas, só dentro de um estreito prisma podem ser configuradas em conformidade com uma vontade política veiculada juridicamente. Tudo leva a acreditar que mais e melhores regras são, no máximo, um bom pretexto para transformações sociais - o que está muito longe das ambições de abordagens jurídicas do tipo “social-engineering.” Um bom simulacro, uma

${ }^{51}$ MOREIRA, Luiz. A Constituição como Simulacro, op. cit., p. 81.

52 "A Constituição é, em primeiro lugar, um a[u]to de fé”, declara cabalmente José Adércio Leite SAMPAIO, Teoria e Prática do Poder Constituinte. Como Legitimar ou Desconstruir 1988 - 15 anos Depois, in SAMPAIO, J. A. L. (coord.), Quinze Anos de Constituição. Belo Horizonte: Del Rey, 2004, p. 59.

${ }^{53}$ Como quer BERCOVICI (O Poder Constituinte do Povo no Brasil, op. cit.): “[o] problema central, ignorado pela maior parte de nossos doutrinadores, é o fato de que a soberania brasileira, como soberania de um Estado periférico, é uma 'soberania bloqueada', ou seja, enfrenta severas restrições externas e internas que a impedem de se manifestar em toda sua plenitude.” 
boa simbologia constitucional, é aquela que dá uma boa fachada para o funcionamento autônomo do direito e da política, e onde houver um sistema de direito positivo constitucionalizado que consiga manter mais do que a aparência de legalidade, é lá que a simulação terá êxito.

Endossar veementemente a soberania popular não nos livra do simulacro, nem nos faz mais modernos - quem sabe mesmo o contrário! Mas não é de todo impossível limitar a vigência ou normatizar uma revisão constante do direito constitucional, desde que não se coloque em questão a aplicabilidade do direito como um todo. Aonde pode conduzir uma tal abertura cognitiva à complexidade, não se sabe, mas a evolução é cega por definição. 